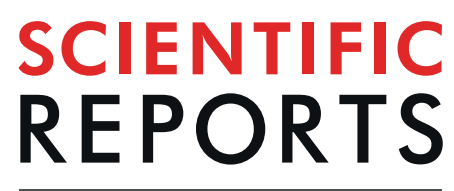

natureresearch

\title{
Bi-functional IgG-lysosomal enzyme fusion proteins for brain drug delivery
}

\author{
Ruben J. Boado, Jeff Zhiqiang Lu, Eric Ka-Wai Hui, Huilan Lin \& William M. Pardridge*
}

Most lysosomal storage disorders affect the central nervous system. However, lysosomal enzymes do not cross the blood-brain barrier (BBB), and intravenous enzyme infusion is not effective for the brain. Lysosomal enzymes can be re-engineered for BBB transport as IgG-enzyme fusion proteins, where the IgG domain is a monoclonal antibody (MAb) against an endogenous BBB receptor/transporter, and which acts as a molecular Trojan horse to deliver the enzyme to brain. However, the problem is retention of high enzyme activity following enzyme fusion to the lgG. The present investigation shows this is possible with a versatile approach that employs fusion of the enzyme to either the IgG heavy chain or light chain using a long flexible linker. The model IgG is a chimeric monoclonal antibody (MAb) against the human insulin receptor (HIR). The enzyme activity of the HIRMAb-enzyme fusion protein is preserved for hexosaminidase $A$, which is mutated in Tay Sachs disease, for protein palmitoylthioesterase-1, which is mutated in Batten disease type 1, acid sphingomyelinase, which is mutated in Niemann Pick disease type A, and beta galactosidase-1, which is mutated in GM1 gangliosidosis.

Lysosomal storage diseases are inborn errors of metabolism caused by mutations in the gene encoding one of $>50$ different lysosomal enzymes, and the majority of these inherited diseases adversely affect the central nervous system $(\mathrm{CNS})^{1}$. In most cases, the cDNA encoding the respective lysosomal enzyme has been cloned, and the recombinant protein has been expressed. However, for most disorders, no intravenous (IV) Enzyme Replacement Therapy (ERT) has been developed because (a) the primary clinical manifestations of the disease are CNS, and (b) the recombinant enzyme does not cross the blood-brain barrier (BBB). For example, Tay Sachs disease (TSD) ${ }^{2}$ is caused by mutations in the gene encoding the hexosaminidase A (HEXA) enzyme ${ }^{3}$, but HEXA does not cross the $\mathrm{BBB}^{4}$. Batten type 1 disease, also known as Ceroid Lipofuscinosis type 1 (CLN1) disease ${ }^{5}$, is caused by mutations in the gene encoding protein palmitoylthioesterase- 1 (PPT1 $)^{6}$, but PPT1 does not cross the $\mathrm{BBB}^{7}$. Niemann Pick disease type A (NPDA) $)^{8}$ is caused by mutations in the gene encoding acid sphingomyelinase (ASM) ${ }^{9}$, also known as sphingomyelin phosphodiesterase-1 (SMPD1), but ASM does not cross the BBB ${ }^{10}$. GM1 gangliosidois $(\mathrm{GM} 1 \mathrm{G})^{11}$ is caused by mutations in the gene encoding beta galactosidase-1 (GLB1) ${ }^{12}$, but GLB1 does not cross the $\mathrm{BBB}^{13}$.

The lysosomal enzymes can be re-engineered to enable BBB transport with the genetic engineering of an IgG-lysosomal enzyme fusion protein, where the $\mathrm{IgG}$ domain is a monoclonal antibody (MAb) directed against an endogenous $\mathrm{BBB}$ receptor-mediated transport system, such as the insulin receptor or the transferrin receptor $^{14}$. The IgG domain acts as a molecular Trojan horse to ferry the enzyme across the BBB and into brain cells. Typically, the lysosomal enzyme is genetically fused to the carboxyl terminus (CT) of the heavy chain (HC) of the IgG with a short, e.g. 3-amino acid (AA) linker ${ }^{14}$.

The challenge in engineering IgG-lysosomal enzyme fusion proteins is the retention of high lysosomal enzyme activity following fusion of the enzyme to the IgG. For example, fusion of the beta glucuronidase (GUSB) enzyme to the CT of the HC of an IgG resulted in $>95 \%$ loss of enzyme activity ${ }^{15}$. Fusion of the enzyme to the amino terminus (NT) of the IgG resulted in retention of high enzyme activity, but this format caused a $>95 \%$ loss of binding of the IgG to the target $\mathrm{BBB}$ receptor ${ }^{15}$, owing to steric hindrance caused by fusion of the enzyme to the IgG NT domain, which is contiguous with the complementarity determining regions (CDR) of the IgG. However, enzyme activity may be retained following fusion to an $\mathrm{IgG}$ with the use of alternative genetic engineering strategies. 
The purpose of the present investigation is to test the versatility of the IgG-enzyme platform with respect to alternative approaches toward the engineering of IgG-enzyme fusion proteins for lysosomal enzymes such as HEXA, PPT1, ASM, and GLB1. The engineering of the IgG-enzyme fusion protein may involve (a) fusion of the enzyme to the CT of either the IgG heavy chain (HC) or the light chain (LC), or (b) the use of either a short linker (SL), or a long linker (LL) between the IgG chain and the enzyme. A long flexible linker provides spatial separation between the IgG and enzyme domains of the fusion protein. A longer linker may be more immunogenic than a short linker. Therefore, the long linker should be comprised of a linker that is both flexible and derived from an existing human protein sequence. These properties are satisfied with the use of a linker derived from the hinge region of human IgG3, which is longer and more flexible than the hinge region of any other human IgG subclass ${ }^{16}$. The model IgG domain is a chimeric MAb against the human insulin receptor (HIR), designated the HIRMAb ${ }^{14}$.

This study shows that HEXA, PPT1, ASM, or GLB1 can be fused to the CT of either the HC or LC of the HIRMAb, and enzyme activity is comparable to the native enzyme with the use of a long flexible linker.

\section{Results}

Nomenclature. The fusion proteins are designated as HIRMAb-LC-LL-HEXA, HIRMAb-HC-SL-PPT1, HIRMAb-HC-LL-PPT1, HIRMAb-LC-LL-ASM, HIRMAb-HC-SL-GLB1, and HIRMAb-HC-LL-GLB1, where the LC or HC designation indicates if the enzyme was fused to the CT of the heavy chain or the light chain, respectively, and the SL and LL designation refers to the presence of either the 3-AA short linker, or the 31-AA long linker, respectively.

Western blotting. The structures of the 4 IgG-enzyme fusion proteins are shown in Fig. 1. The HEXA and the ASM are fused to the CT of the light chain of the HIRMAb, and PPT1 and GLB1 are fused to the CT of the heavy chain of the HIRMAb. Following protein A affinity chromatography, each fusion protein migrated on reducing SDS-PAGE with a single heavy chain (HC) and single light chain (LC). The Western blots (WB) for the 4 fusion proteins are shown in Fig. 2. For the HEXA fusion protein, the anti-human IgG WB detected a $56 \mathrm{kDa}$ HC for both the HIRMAb (lane 1) and the HIRMAb-LC-LL-HEXA (lane 2), and detected a $26 \mathrm{kDa}$ LC for the HIRMAb (lane 1) and a $102 \mathrm{kDa}$ LC for the HIRMAb-LC-LL-HEXA (lane 2) (Fig. 2a, left panel). For the HEXA fusion protein, the anti-HEXA WB detected the $102 \mathrm{kDa}$ HIRMAb-LC-LL-HEXA (lane 3) and showed no reaction with the HIRMAb (lane 4) (Fig. 2a, right panel). For the PPT1 fusion protein, the anti-human IgG WB detected a $56 \mathrm{kDa}$ HC for the HIRMAb and a $99 \mathrm{kDa}$ HC for the HIRMAb-HC-LL-PPT1, and detected a $26 \mathrm{kDa}$ LC for both the HIRMAb (lane 1) and HIRMAb-HC-LL-PPT1 (lane 2) (Fig. 2b, left panel). For the PPT1 fusion protein, the anti-PPT1 WB detected only the $99 \mathrm{kDa}$ HIRMAb-HCC-LL-PPT1 (lane 3) (Fig. 2b, right panel). For the ASM fusion protein, the anti-human IgG WB detected a $56 \mathrm{kDa} \mathrm{HC}$ for both the HIRMAb and the HIRMAb-LC-LL-ASM, and detected $26 \mathrm{kDa}$ LC for the HIRMAb (lane 1) and a $105 \mathrm{kDa}$ LC for the HIRMAb-LC-LL-ASM (lane 2) (Fig. 2c, left panel). For the ASM fusion protein, the anti-ASM WB detected the $105 \mathrm{kDa}$ HIRMAb-LC-LL-ASM (lane 4) and showed no reaction with the HIRMAb (lane 3) (Fig. 2c, right panel). For the GLB1 fusion protein, the anti-human IgG WB detected a $56 \mathrm{kDa}$ HC for the HIRMAb and a $140 \mathrm{kDa}$ HC for the HIRMAb-HC-LL-GLB1, and detected a $26 \mathrm{kDa}$ LC for both the HIRMAb (lane 1) and HIRMAb-HC-LL-GLB1 (lane 2) (Fig. 2d, left panel). For the GLB1 fusion protein, the anti-GLB1 WB showed no reaction with the HIRMAb (lane 3), but detected the $140 \mathrm{kDa}$ HIRMAb-HC-LL-GLB1 (lane 4) (Fig. 2d, right panel). The MWs estimated from the WB are given in Table 1 for the HC, the LC, and the tetramer, in comparison with the MWs of the non-glycosylated fusion proteins estimated from the amino acid sequence.

HIR binding. The binding of the HIRMAb and the HIRMAb-LC-LL-HEXA fusion protein to the HIR is shown in Fig. 3. The HIR binding of the respective HIRMAb-enzyme fusion proteins were determined in 4 separate ELISAs, using the HIRMAb alone as control, and these ED50 values are listed in Table 2. The ED50 was initially measured as $\mathrm{ng} / \mathrm{mL}$, and was converted to $\mathrm{nM}$, based on the $\mathrm{MW}$ of the tetramer determined by Western blotting (Table 1 ). The ED50 of the HIRMAb alone varied within a narrow range of $0.23-0.32 \mathrm{nM}$ (Table 1 ). The ED50 of 3 of the HIRMAb-enzyme fusion proteins also varied within a narrow range of $0.35-0.38 \mathrm{nM}$, the one exception being the ED50, $0.93 \mathrm{nM}$, of the HIRMAb-ASM fusion protein, which still represents a high affinity for the HIR.

Enzyme activity. The enzyme activity of each fusion protein was measured with flurometric assays and enzyme-specific substrates (Table 3), and the specific activity for each fusion protein is given in Table 3. Using the 4-MUG substrate, the HEXA activity of HIRMAb-LC-LL-HEXA was comparable to recombinant HEXA. The ratio of HEXA enzyme activity of the HIRMAb-LC-LL-HEXA fusion protein with the 4-MUG substrate, relative to the 4-MUGS substrate, was 1.5 (Table 3). Initially, the HIRMAb-HC-PPT1 fusion protein was engineered with the short linker (SL), but this HIRMAb-HC-SL-PPT1 fusion protein demonstrated low PPT1 enzyme activity (Table 3). Subsequently, this fusion protein was re-engineered with the long linker (LL), and the HIRMAb-HC-LL-PPT1 fusion protein exhibited high PPT1 enzyme activity (Table 3). The HIRMAb-LC-LL-ASM fusion protein showed high enzyme activity against the HMU-PC substrate (Table 3 ). Initially, the HIRMAb-HC-GLB1 fusion protein was engineered with the SL short linker, but this HIRMAb-HC-SL-GLB1 fusion protein demonstrated reduced GLB1 enzyme activity compared to human recombinant GLB1 (Table 3). Subsequently, this fusion protein was re-engineered with the long LL linker, and the HIRMAb-HC-LL-GLB1 fusion protein exhibited high GLB1 enzyme activity (Table 3). 

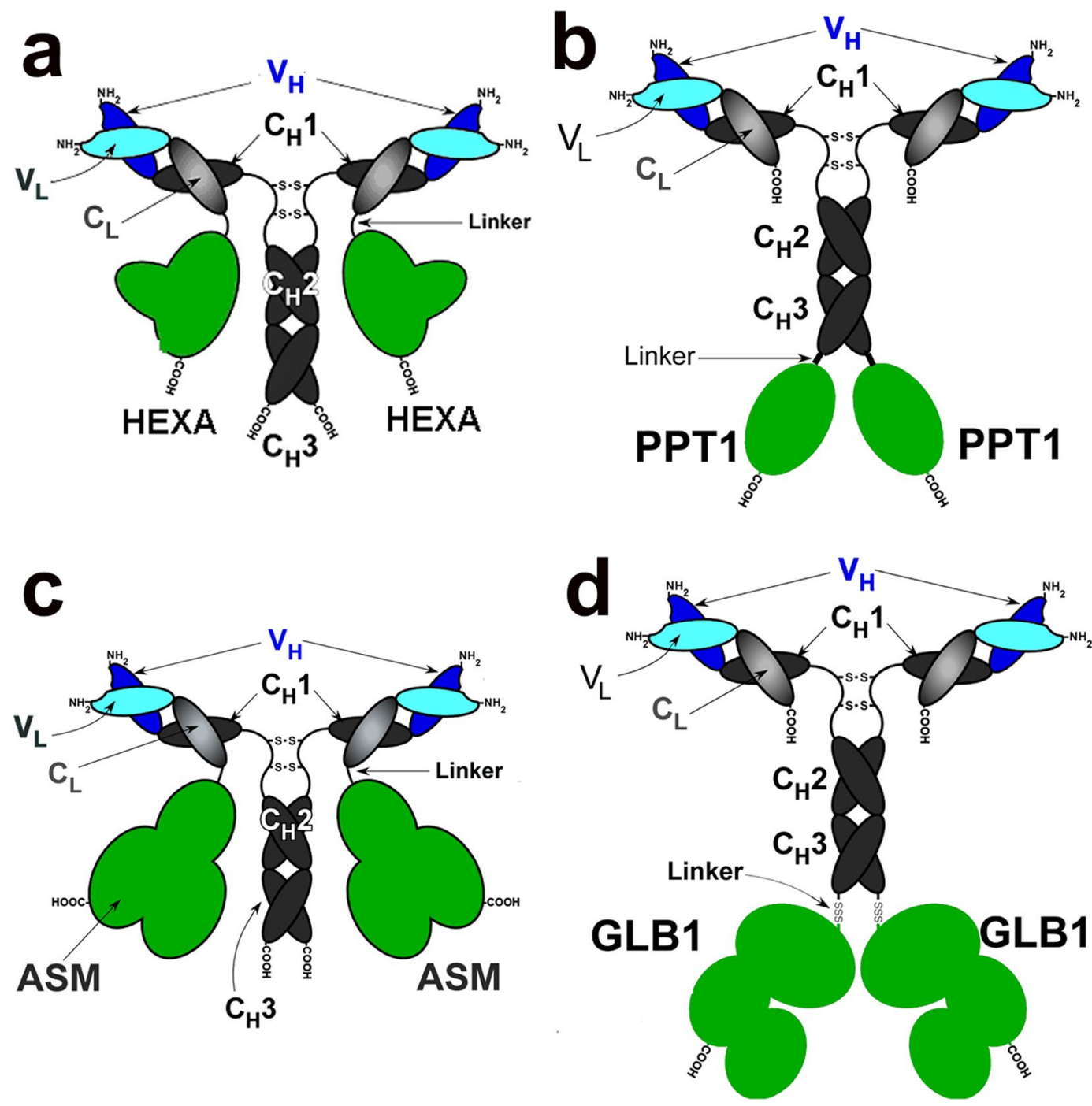

Figure 1. (a) Structure of HIRMAb-LC-LL-HEXA, where the HEXA enzyme is fused to the CT of the light chain (LC) of the HIRMAb via a 31-amino acid long linker (LL). (b) Structure of HIRMAb-HC-LL-PPT1, where the PPT1 enzyme is fused to the CT of the heavy chain (HC) of the HIRMAb via the LL linker. (c) Structure of HIRMAb-LC-LL-ASM, where the ASM enzyme is fused to the CT of the LC of the HIRMAb via the LL linker. (d) Structure of HIRMAb-HC-LL-GLB1, where the GLB1 enzyme is fused to the CT of the HC of the HIRMAb via the $L L$ linker. $V_{H}=$ variable region of $H C ; V_{L}=$ variable region of $L C ; C_{L}=$ constant region of $L C$; $\mathrm{C}_{\mathrm{H}} 1, \mathrm{C}_{\mathrm{H}} 2$, and $\mathrm{C}_{\mathrm{H}} 3$ are domains of the constant region of the $\mathrm{HC}$.

\section{Discussion}

This investigation describes the genetic engineering of 4 bi-functional IgG-lysosomal enzyme fusion proteins, where the IgG domain is the chimeric HIRMAb and the lysosomal enzyme domain is comprised of human HEXA, PPT1, ASM, or GLB1. Each of these lysosomal enzymes are mutated in TSD, CLN1, NPDA, or GM1G, respectively ${ }^{2,5,8,11}$. All 4 of these lysosomal storage disorders have severe CNS clinical manifestations ${ }^{2,5,8,11}$ and conventional ERT is not possible, because the enzymes do not cross the BBB. Prior work has shown that the HIRMAb does cross the BBB via RMT on the endogenous BBB insulin receptor, and delivers a fused lysosomal enzyme to the primate brain with a brain uptake of $1 \%$ injected dose (ID)/brain ${ }^{17,18}$. As discussed below, this level of brain uptake produces therapeutic levels of lysosomal enzyme activity in the brain, providing the activity of the respective lysosomal enzyme is retained following genetic fusion of the enzyme to the HIRMAb. IgG-lysosomal enzymes are triaged to the lysosomal compartment ${ }^{17}$, and reduce lysosomal inclusion bodies in both peripheral organs and the brain following systemic administration in mouse models of lysosomal storage disease $\mathrm{e}^{19,20}$. The HIRMAb-enzyme fusion proteins have dual receptor specificity and, in addition to binding the insulin receptor, also bind the mannose 6-phosphate $(\mathrm{M} 6 \mathrm{P})$ receptor $(\mathrm{M} 6 \mathrm{PR})^{18}$. The HIRMAb-enzyme fusion proteins are targeted to somatic tissues via the M6PR and to the CNS via the BBB insulin receptor ${ }^{18}$. HEXA, PPT1, ASM, and GLB1 all incorporate $\mathrm{M}^{2} \mathrm{P}^{21}$. The HIRMAb-iduronidase (IDUA) fusion protein, valanafusp alpha, has an excellent safety profile in humans over the course of 52 weeks of treatment of Mucopolysaccharidosis (MPS) Type I (MPSI), and 


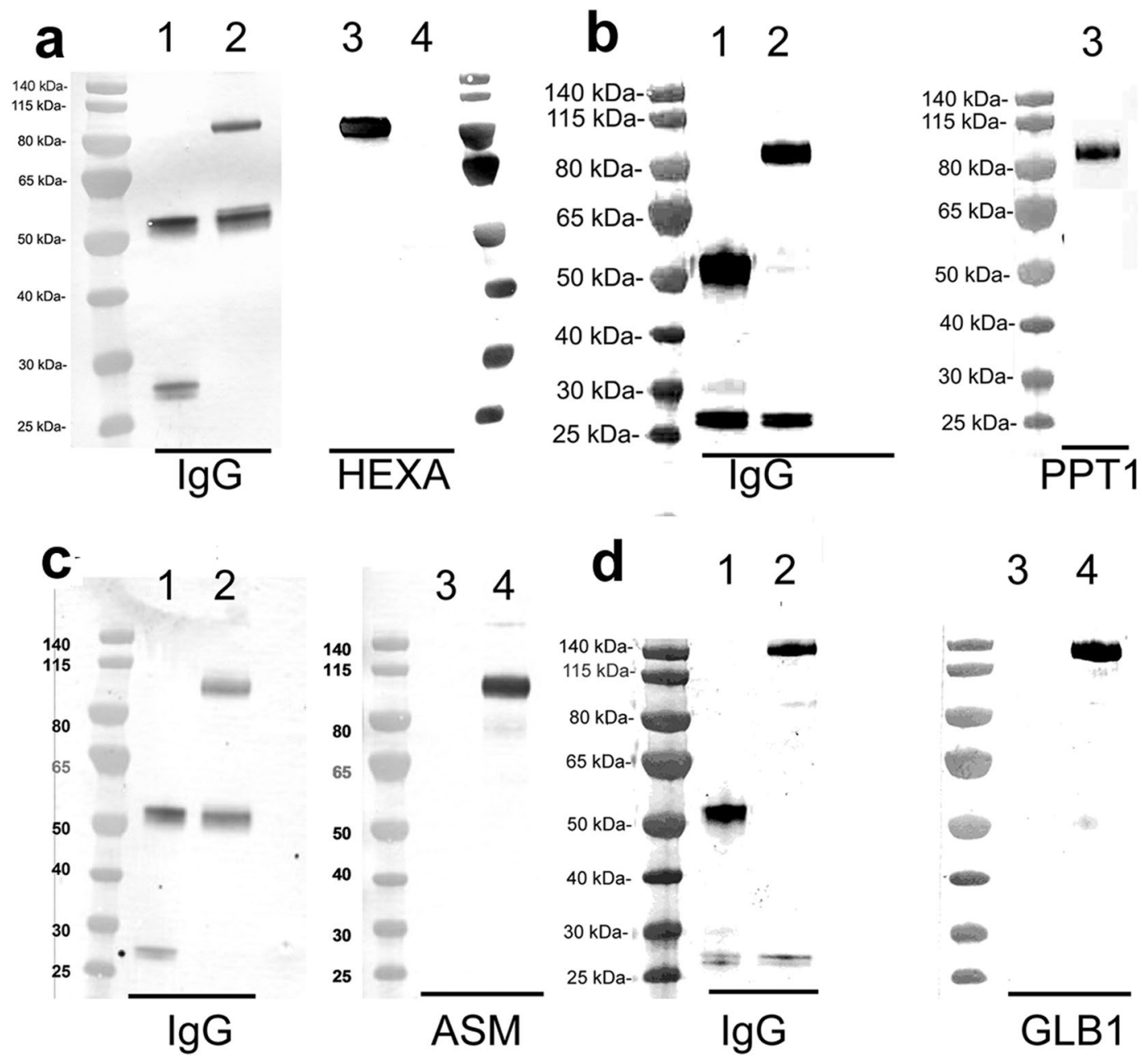

Figure 2. (a) Western blot (WB) of the HIRMAb (lanes 1,4) and the HIRMAb-LC-LL-HEXA fusion protein (lanes 2,3) probed with a primary antibody against either human IgG (left panel, lanes 1,2) or against human HEXA (right panel, lanes, 3,4). (b) WB of the HIRMAb (lane 1) and the HIRMAb-HC-LL-PPT1 fusion protein (lanes 2,3) probed with a primary antibody against either human IgG (left panel, lanes 1,2) or against human PPT1 (right panel, lane 3). (c) WB of the HIRMAb (lanes 1,3) and the HIRMAb-LC-LL-ASM fusion protein (lanes 2,4) probed with a primary antibody against either human IgG (left panel, lanes 1,2) or against human ASM (right panel, lanes 3,4). (d) WB of the HIRMAb (lanes 1,3) and the HIRMAb-HC-LL-GLB1 fusion protein (lanes 2,4 probed with a primary antibody against either human IgG (left panel, lanes 1,2) or against human GLB1 (right panel, lanes 3,4).

\begin{tabular}{|l|l|l|l|}
\hline \multirow{4}{*}{ Fusion protein } & \multirow{2}{*}{ Chain/tetramer } & Molecular weight \\
\cline { 3 - 4 } & Heavy chain & 48,611 & 56,000 \\
\hline \multirow{4}{*}{ HIRMAb LC-LL- HEXA } & Light chain & 84,881 & 102,000 \\
\cline { 2 - 4 } & tetramer & 266,984 & 316,000 \\
\hline \multirow{3}{*}{ HIRMAb-HC-LL-PPT1 } & Heavy chain & 82,869 & 99,000 \\
\cline { 2 - 4 } & Light chain & 23,402 & 26,000 \\
\cline { 2 - 4 } & tetramer & 212,542 & 250,000 \\
\hline \multirow{3}{*}{ HIRMAb-HC-LL-GLB1 } & Heavy chain & 48,611 & 56,000 \\
\cline { 2 - 4 } & Light chain & 89,787 & 105,000 \\
\cline { 2 - 4 } & tetramer & 276,796 & 322,000 \\
\hline & Heavy chain & 125,176 & 140,0000 \\
\cline { 2 - 4 } & tetramer & 297,156 & 332,000 \\
\hline
\end{tabular}

Table 1. Molecular weights of fusion protein chains and tetramers computed from either the predicted amino acid (AA) sequence or by Western blotting (Fig. 2). 


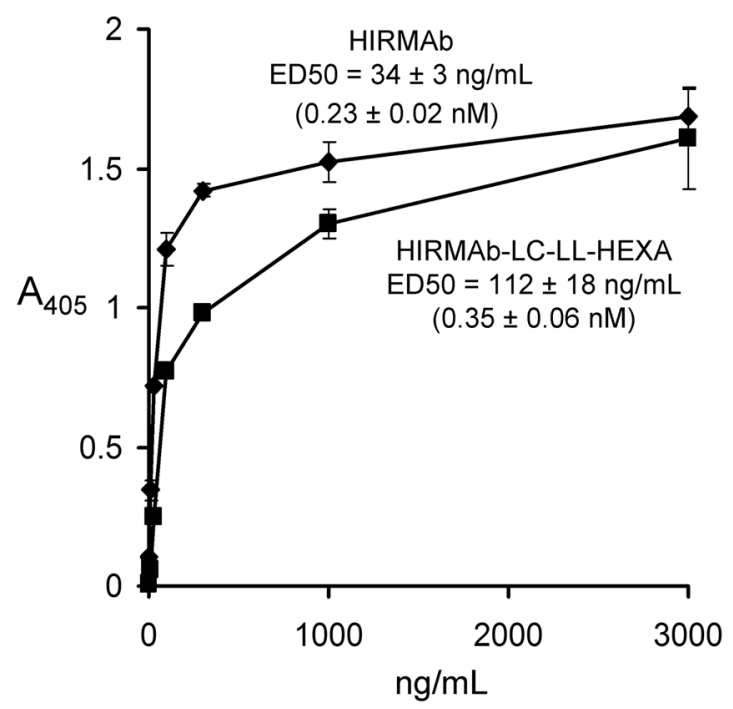

Figure 3. Binding of HIRMAb or HIRMAb-LC-LL-HEXA as determined by ELISA where the capture agent is the extracellular domain of the recombinant human insulin receptor (HIR) and the detector reagent is a conjugate of alkaline phosphatase and a goat anti-human IgG-Fc antibody. The ED50 was determined by nonlinear regression analysis.

\begin{tabular}{|l|l|l|}
\hline Assay & Protein & HIR ED50 $(\mathbf{n M})$ \\
\hline \multirow{3}{*}{1} & HIRMAb & $0.23 \pm 0.02$ \\
\cline { 2 - 3 } & HIRMAb-LC-LL-HEXA & $0.35 \pm 0.06$ \\
\hline \multirow{2}{*}{2} & HIRMAb & $0.26 \pm 0.04$ \\
\cline { 2 - 3 } & HIRMAb-HC-LL-PPT1 & $0.38 \pm 0.11$ \\
\hline \multirow{2}{*}{3} & HIRMAb & $0.32 \pm 0.11$ \\
\cline { 2 - 3 } & HIRMAb-LC-LL-ASM & $0.93 \pm 0.12$ \\
\hline \multirow{2}{*}{4} & HIRMAb & $0.25 \pm 0.04$ \\
\cline { 2 - 3 } & HIRMAb-HC-LL-GLB1 & $0.36 \pm 0.05$ \\
\hline
\end{tabular}

Table 2. Fusion protein binding to human insulin receptor (HIR) as determined by ELISA using the HIR extracellular domain as capture agent. ED50 values are mean \pm SE, as determined by non-linear regression analysis of saturation curves such as shown in Fig. 3.

stabilizes both somatic and CNS function in children with MPSI at weekly intravenous infusion doses of 1-6 mg/ $\mathrm{kg}^{22}$.

The lysosomal enzyme can be fused to the C-terminus of either the heavy chain (HC) or the light chain (LC) of the IgG domain. Fusion to the HC places the enzyme in a dimeric configuration, whereas fusion to the LC places the enzyme in a more flexible, monovalent configuration. Enzymes such as $\mathrm{PPT}^{23}{ }^{2}$ or $\mathrm{GLB}^{24}$ form homo-dimers, and these enzymes were fused to the C-terminus of the HC (Fig. 1b,d). Conversely, enzymes such as HEXA or ASM form hetero-dimers with activator proteins, such as GM2 activator protein ${ }^{25}$ or saposin $\mathrm{C}^{26}$, respectively, and these enzymes were fused to the C-terminus of the LC (Fig. 1a,c).

TSD is a severe childhood form of neurodegeneration of the brain and spinal cord leading to psychomotor retardation, seizures, deafness, and death in early childhood ${ }^{2}$. The cDNA encoding human HEXA was published in $1985^{3}$. HEXA does not cross the $\mathrm{BBB}^{4}$, so intravenous ERT of TSD is not possible. The HIRMAb-HEXA fusion protein retains both high affinity binding to the HIR (Table 2) and HEXA enzyme activity comparable to recombinant HEXA (Table 3). The normal HEXA enzyme activity in brain, as determined with the same substrate, 4-MUGS, used in this study, is $10.8 \mathrm{nmol} /$ hour $/ \mathrm{mgp}^{27}$, which is equivalent to 18 milliunits/gram, where $1 \mathrm{mU}=1$ $\mathrm{nmol} / \mathrm{min}$, and 1 gram brain is equal to $100 \mathrm{mg}$ protein (mgp $)^{28}$. The HEXA enzyme activity administered with an ID of $3 \mathrm{mg} / \mathrm{kg}$ of the HIRMAb-LC-LL-HEXA fusion protein, in a $50 \mathrm{~kg}$ human, is equivalent to $250,000 \mathrm{mil}-$ liunits, given the specific activity of $1636 \mathrm{mU} / \mathrm{mg}$ for this fusion protein (Table 3). With a brain uptake of $1 \%$ ID/ brain, and a $1000 \mathrm{~g}$ human brain, the HEXA activity delivered to brain is 2500 milliunits/brain, or 2.5 milliunits/ gram, which is $23 \%$ of normal endogenous HEXA activity in brain. The replacement of only $1-2 \%$ of endogenous lysosomal enzyme activity is sufficient to reverse the course of the disease ${ }^{29}$. The replacement of $1-5 \%$ of HEXB enzyme activity in the Sandhoff mouse is sufficient to reverse ganglioside storage and to prolong life ${ }^{30}$.

CLN1 is a severe form of Batten disease associated with neurodegeneration, muscle weakness, blindness, seizure and early death in childhood ${ }^{5}$. The cDNA encoding human PPT1 was published in $1994^{6}$. Human PPT1 has been expressed in CHO cells as a $34 \mathrm{kDa}$ protein ${ }^{31}$, with an enzyme activity of $15 \mathrm{units} / \mathrm{mg}^{32}$, 


\begin{tabular}{|c|c|c|c|}
\hline Substrate & IgG-enzyme or enzyme & Enzyme activity & Units of activity \\
\hline \multirow[t]{2}{*}{ 4-methylumbelliferyl-2-acetamido-2-deoxy- $\beta$-D-glucopyranoside (4-MUG) } & $\begin{array}{l}\text { HIRMAb-LC- } \\
\text { LL-HEXA }\end{array}$ & $2,464 \pm 109$ & \multirow{3}{*}{$\mathrm{mU} / \mathrm{mg}$ protein } \\
\hline & HEXA & $2,557 \pm 187$ & \\
\hline $\begin{array}{l}\text { 4-Methylumbelliferyl-7-(6-sulfo-2-acetamido-2-deoxy- } \beta \text {-D-glucopyranoside } \\
\text { (4-MUGS) }\end{array}$ & $\begin{array}{l}\text { HIRMAb-LC- } \\
\text { LL-HEXA }\end{array}$ & $1,636 \pm 203$ & \\
\hline \multirow{2}{*}{$\begin{array}{l}\text { 4-methylumbelliferyl 6-thio-palmitate- } \beta \text {-D-glucopyranoside } \\
\text { (Mu-6S-Palm-beta-Glc) }\end{array}$} & $\begin{array}{l}\text { HIRMAb-HC- } \\
\text { SL-PPT1 }\end{array}$ & $53 \pm 15$ & \multirow{2}{*}{$\mathrm{mU} / \mathrm{mg}$ protein } \\
\hline & $\begin{array}{l}\text { HIRMAb-HC- } \\
\text { LL-PPT1 }\end{array}$ & $1742 \pm 75$ & \\
\hline 6-hexadecanoylamino-4-methylumbelliferyl phosphocholine (HMU-PC) & HIRMAb-LC- LL-ASM & $902 \pm 41$ & $\mathrm{mU} / \mathrm{mg}$ protein \\
\hline \multirow{3}{*}{$\begin{array}{l}\text { 4-methylumbelliferyl } \beta \text {-D-galactopyranoside } \\
\text { (MUGP) }\end{array}$} & $\begin{array}{l}\text { HIRMAb-HC- } \\
\text { SL-GLB1 }\end{array}$ & $49,000 \pm 12,000$ & \multirow{3}{*}{ units/mg protein } \\
\hline & $\begin{array}{l}\text { HIRMAb-HC- } \\
\text { LL-GLB1 }\end{array}$ & $171,000 \pm 23,000$ & \\
\hline & GLB1 & $183,000 \pm 56,000$ & \\
\hline
\end{tabular}

Table 3. Lysosomal enzyme activity of fusion proteins as determined with enzyme-specific substrates and enzymatic fluorometric assays. Enzyme activity units are: 1 milliunit $(\mathrm{mU})=1 \mathrm{nmol}$ per minute for HEXA; 1 $\mathrm{mU}=1 \mathrm{nmol}$ per minute for PPT1; $1 \mathrm{mU}=1 \mathrm{nmol}$ per minute for ASM; 1 unit=1 nmol per hour for GLB1. Values are mean $\pm \mathrm{SE}(\mathrm{N}=3$ replicates).

using the same Mu-6S-Palm-betaGlc substrate used in this study (Table 3). The PPT1 specific activity of the HIRMAb-HC-LL-PPT1 fusion protein is 1.7 units/mg (Table 3). However, the MW of the fusion protein half-tetramer, $125 \mathrm{kDa}$ (Table 1), is 4-fold greater than the MW of the PPT1 monomer; therefore, on a molar basis, the PPT1 enzyme activity is $46 \%$ of the activity of recombinant human PPT1. PPT1 does not cross the BBB ${ }^{7}$, and intravenous ERT of the brain with recombinant PPT1 is not possible. The PPT1 enzyme has been delivered to brain of the CLN1 mouse via intra-cerebroventricular (ICV) injection ${ }^{7}$. However, ICV administration only delivers enzyme to the surface of the brain, as demonstrated in primates following the ICV infusion of very high doses of the lysosomal enzyme ${ }^{33}$. Treatment of the entire parenchyma of brain is possible with transvascular delivery of PPT1 across the BBB. The normal brain PPT1 enzyme activity is $70 \mathrm{nmol} / \mathrm{hour} / \mathrm{mgp}$ using the Mu-6S-Palm-betaGlc substrate ${ }^{34}$, which is equal to $116 \mathrm{mU} / \mathrm{gram}$, where $1 \mathrm{mU}=1 \mathrm{nmol} / \mathrm{min}$, and 1 gram brain is equal to $100 \mathrm{mgp}$. The PPT1 enzyme activity administered with an ID of $3 \mathrm{mg} / \mathrm{kg}$ of the HIRMAb-HC-LL-PPT1 fusion protein, in a $50 \mathrm{~kg}$ human, is equivalent to an ID of 260,000 milliunits, given the specific activity of 1742 $\mathrm{mU} / \mathrm{mg}$ for this fusion protein (Table 3). With a brain uptake of $1 \% \mathrm{ID} / \mathrm{brain}$, and a $1000 \mathrm{~g}$ human brain, the PPT1 activity delivered to brain is 2600 milliunits/brain, or 2.6 milliunits/gram, which is $2.2 \%$ of normal endogenous PPT1 activity in brain. A brain PPT1 activity as low as $0.5 \%$ of endogenous activity is sufficient to reverse the neuropathology of CLN disease $\mathrm{e}^{35}$.

NPDA is a neurodegenerative condition leading to muscle weakness, mental retardation, seizures, and early death in childhood ${ }^{8}$. The cDNA encoding human ASM was published in $1989^{9}$. Estimates of the enzyme activity of recombinant ASM with the HMU-PC substrate used in this study are not readily available, although the activity of $902 \mathrm{mU} / \mathrm{mg}$ for the HIRMAb-LC-LL-ASM fusion protein (Table 3) is comparable to the activity of recombinant ASM, $1700 \mathrm{mU} / \mathrm{mg}$, as determined with a similar substrate, 2-N-hexadecanoylamino4-nitrophenylphosphorylcholine (R\&D Systems, Minneapolis, MN). The MW of the half-tetramer of the HIRMAb-LC-LL-ASM fusion protein, $161 \mathrm{kDa}$, is nearly 2-fold greater the MW of recombinant human ASM, $75 \mathrm{kDa}^{36}$. Therefore, the ASM activity of the HIRMAb-LC-LL-ASM fusion protein is comparable to recombinant ASM. The ASM activity in brain with the HMU-PC substrate is not readily available. However, intracerebral injection of adeno-associated virus encoding ASM produces ASM brain at levels of 0.4-1.9 ug/gram, and this reverses neuropathology in the ASM knockout mouse ${ }^{37}$. The administration of $3 \mathrm{mg} / \mathrm{kg}$ of the HIRMAb-LC-LL-ASM fusion protein in a $50 \mathrm{~kg}$ human is expected to produce a brain concentration of the fusion protein of $1 \% \mathrm{ID} / \mathrm{brain}$, or $1500 \mathrm{ug} / \mathrm{brain}$ or $1.5 \mathrm{ug} / \mathrm{gram}$ brain, which is a therapeutic enzyme level in the brain of the NPDA mouse ${ }^{37}$.

GM1G infants are afflicted with neurodegeneration, seizures, ataxia, and blindness followed by early death in childhood ${ }^{11}$. The cDNA encoding human GLB1 was published in $1988^{12}$. Recombinant GLB1 has been expressed in CHO cells with a specific activity of 240,000 units $/ \mathrm{mg}^{38}$, using the MUGP substrate, and this value is not significantly different from the specific activity of commercially available recombinant human GLB1 (Table 3). The MW of CHO derived GLB1 is $88 \mathrm{kDa}^{39}$, which is nearly 2-fold lower than the MW of the half-tetramer of the HIRMAb-HC-LL-GLB1 fusion protein (Table 3). The endogenous GLB1 enzyme activity in brain, using the MUGP substrate, is 57 units/mgp ${ }^{40}$, which is comparable to 5700 units/gram brain, assuming 1 gram brain is 100 mgp. The GLB1 enzyme activity administered with an ID of $3 \mathrm{mg} / \mathrm{kg}$ of the HIRMAb-HC-LL-GLB1 fusion protein, in a $50 \mathrm{~kg}$ human, is equivalent to 25.6 million units, given the specific activity of $171,000 \mathrm{units} / \mathrm{mg}$ (Table 3 ). With a brain uptake of $1 \%$ ID/brain, and a $1000 \mathrm{~g}$ human brain, the GLB1 activity delivered to brain is 256,000 units/brain, or 256 units/gram, which is $4.5 \%$ of normal endogenous GLB1 activity in brain. This level of GLB1 activity in brain may be therapeutic as GLB1 activity at the $10 \%$ of normal level is sufficient to lower brain GM1 ganglioside ${ }^{41}$. Higher levels of GLB1 enzyme activity are possible with injection doses $>3 \mathrm{mg} / \mathrm{kg}$.

The immunogenicity, or effector function, of HIRMAb-enzyme fusion proteins has been examined in humans following a year of chronic administration, and the immunogenicity of the fusion protein is no greater than the 
immunogenicity of the enzyme alone, and no clinical signs of effector function were observed ${ }^{22}$. The insertion of the IgG3 hinge region in engineered antibodies does not increase effector function ${ }^{42}$.

In summary, the present investigation shows that a diverse group of lysosomal enzymes can be successfully fused to either the LC or the HC of the HIRMAb and that high enzyme activity is retained with the use of 31-AA long linker between the IgG and enzyme domains. This linker is expected to be stable in vivo and not to be immunogenic as the sequence is derived from the human IgG3 hinge region. Fusion of the lysosomal enzyme to a BBB molecular Trojan horse, such as the HIRMAb, enables the intravenous ERT of the brain in these serious childhood inborn errors of metabolism.

\section{Methods}

Genetic engineering and production of HIRMAb-lysosomal enzyme fusion proteins. The HEXA domain corresponded to Leu-23 to Thr-529 of human HEXA (NP_000511); the PPT1 domain corresponded to Asp-28 to Gly-306 of human PPT1 (NP_000301); the ASM domain corresponded to His-62 to Pro-628 of human ASM (NP_000534); the GLB1 domain corresponded to Leu-24 to Val-677 of human GLB1 (NP_000395). The $\mathrm{HC}$ of the HIRMAb is comprised of a $113 \mathrm{AA}$ variable region of the heavy chain $(\mathrm{VH})$ followed by the constant (C)-region of human IgG1; the LC of the HIRMAb is comprised of a 108 AA variable region of the light chain (VL) followed by the C-region of the human kappa light chain. The linker joining the CT of either the HC or LC was either a short, (Ser)3 linker or a long 31-AA linker. The 31 AA linker includes 25 AA from the human IgG3 hinge region, and is derived from the $12 \mathrm{AA}$ of the upper hinge region, followed by $5 \mathrm{AA}$ of the first part of the core hinge region, followed by $8 \mathrm{AA}$ of the lower hinge region, and is flanked by a Ser-Ser-Ser sequence on the amino terminus and a Ser-Ser-Ser sequence on the carboxyl terminus of the linker, as discussed previously ${ }^{43}$. The 2 cysteine residues of the first part of the core hinge region are mutated to serine residues, so as to eliminate disulfide bonding. The first Leu of the lower hinge is mutated to Phe to eliminate complement fixation ${ }^{42}$. A synthetic gene encoding the lysosomal enzyme and linker was produced at GenScript (Piscataway, NJ), and subcloned into a HIRMAb HC or LC expression plasmid under the influence of a hybrid cytomegalovirus promoter and the bovine growth hormone polyA sequence, which also contained an expression cassette encoding for dihydrofolate reductase to allow of selection of stably transected Chinese hamster ovary (CHO) lines with methotrexate. The genetic engineering of all expression plasmids was confirmed by agarose gel electrophoresis following digestion with specific restriction endonucleases, and bidirectional DNA sequencing using custom primers. The molecular weights (MW) of the non-glycosylated fusion protein were predicted from the amino acid sequence, and the MWs for the HC, the LC, and the tetramer are given in Table 1.

COS cells were transiently transfected with Lipofectamine 2000. Stably transfected CHO lines in serum free medium were cloned following dual electroporation with the $\mathrm{HC}$ and LC expression plasmids. CHO lines were subjected to 1 cell/well dilutional cloning, and the IgG expression ranged from $10-100 \mathrm{mg} / \mathrm{L}$ in shake flasks with a cell density of approximately $10^{5}-10^{6}$ cells $/ \mathrm{mL}$.

$\mathrm{CHO}$ cells were cultured in shake flasks, and the IgG-enzyme fusion protein was purified from this conditioned medium by protein A affinity chromatography. The purity and identity of each fusion protein was examined by reducing sodium dodecylsulfate polyacrylamide gel electrophoresis (SDS-PAGE), and Western blotting (WB), respectively. The primary antibody for the human IgG WB was a goat anti-human IgG $(\mathrm{H}+\mathrm{L})$ antibody (Vector Labs, Burlingame, CA), and the secondary antibody was a biotinylated horse anti-goat IgG (Vector). The primary antibody for the enzyme WB was a mouse anti-human HEXA, a goat anti-human ASM, and a mouse anti-human GLB1 (all from R\&D Systems, Minneapolis, MN), and a mouse anti-human PPT1 antibody (Abcam, Cambridge, MA), and the secondary antibody was either a biotinylated horse anti-mouse IgG or a biotinylated horse anti-goat IgG (Vector Labs).

Human insulin receptor binding assay. The binding avidity of the fusion protein for the HIR was determined by ELISA. The capture agent is the HIR extracellular domain from R\&D Systems (Minneapolis, MN), and the detector agent is a conjugate of alkaline phosphatase and a goat anti-human IgG-Fc antibody (Abcam, Carmbridge, MA). The concentration of either HIRMAb alone, or HIRMAb-enzyme fusion protein, that caused $50 \%$ of maximal binding, the EC50, was determined by non-linear regression analysis by fitting the data to: Absorbance $=($ Amax $\cdot S) /(E C 50+S)$, where Amax is the maximal absorbance and $S=$ the concentration of IgG or fusion protein. The EC50 was estimated with the units of $\mathrm{ng} / \mathrm{mL}$, and converted to units of $\mathrm{nM}$, based on the molecular weight (MW) as determined by migration in reducing SDS-PAGE.

Lysosomal enzyme activity assays. The HEXA flurometric enzymatic assay was performed as described using either 0.5 mM 4-methylumbelliferyl-N-acetyl- $\beta$-D-glucosaminide (4-MUG, Sigma-Aldrich, St Louis, MO) or 0.5 mM 4-Methylumbelliferyl-7-(6-sulfo-2-acetamido-2-deoxy- $\beta$-D-glucopyranoside) (4-MUGS, Toronto Research Chemicals) as the assay substrate ${ }^{44}$. The assay buffer was $100 \mathrm{mM} \mathrm{Na}$ citrate, $250 \mathrm{mM} \mathrm{NaCl}, \mathrm{pH}=4.5$; incubations were performed for $20 \mathrm{~min}$ at $37 \mathrm{C}$ and terminated with alkaline stop solution; enzyme activity is defined as 1 milliunit $=1 \mathrm{nmol} / \mathrm{min}$. Recombinant human HEXA was obtained from R\&D Systems (Minneapolis, $\mathrm{MN})$. The PPT1 fluorometric enzymatic assay was performed as described using $0.64 \mathrm{mM} 4$-methylumbelliferyl 6-thio-palmitate- $\beta$-D-glucopyranoside (Mu-6S-Palm-beta-Glc) as assay substrate ${ }^{45}$, and McIlvaine's phosphate/ citrate buffer at $\mathrm{pH}=4.0 / 15 \mathrm{mM}$ dithiothreitol $/ 0.375 \%$ Triton $\mathrm{X}-100$, and 5 units $/ \mathrm{mL}$ of beta-glucosidase (Sigma G4511, St Louis, Mo) as assay buffer; incubations were performed for $60 \mathrm{~min}$ at $37 \mathrm{C}$ and terminated with alkaline stop solution; enzyme activity is defined as $1 \mathrm{milliunit}=1 \mathrm{nmol} / \mathrm{min}$. The ASM fluorometric enzymatic assay was performed as described using $0.64 \mathrm{mM}$ 6-hexadecanoylamino-4-methylumbelliferyl phosphorylcholine (HMU-PC, Toronto Research Chemicals) as assay substrate ${ }^{46}$, and $0.1 \mathrm{M}$ sodium acetate $/ \mathrm{pH}=5.2 / 0.2 \%$ sodium taurocholate as assay buffer; incubations were performed for $60 \mathrm{~min}$ at $37 \mathrm{C}$ and terminated with alkaline stop solution; enzyme activity is defined as 1 milliunit $=1 \mathrm{nmol} / \mathrm{min}$. The GLB1 fluorometric enzymatic assay was 
performed as described using $0.64 \mathrm{mM}$ 4-Methylumbelliferyl $\beta$-D-glucopyranoside (MUGP, Sigma) as assay substrate $^{39}$, and $50 \mathrm{mM} \mathrm{Na}$ citrate, $\mathrm{pH}=3.5$ as assay buffer; incubations were performed for $20 \mathrm{~min}$ at $37 \mathrm{C}$ and terminated with alkaline stop solution; enzyme activity is defined as 1 unit $=1 \mathrm{nmol} /$ hour. Recombinant human GLB1 from CHO cells was obtained from R\&D Systems. For each of the 4 assays, a standard curve was produced with 0.01 to $3 \mathrm{nmol} /$ tube of 4-methylumbelliferone (4-MU, Sigma-Aldrich). All assays were linear with respect to amount of enzyme added per tube in the range of 10 to $300 \mathrm{ng} /$ tube.

Received: 4 July 2019; Accepted: 3 October 2019;

Published online: 09 December 2019

\section{References}

1. Pastores, G. M. \& Maegawa, G. H. Clinical neurogenetics: neuropathic lysosomal storage disorders. Neurol Clin. 31(4), 1051-71 (2013 Nov).

2. Barritt, A. W., Anderson, S. J., Leigh, P. N. \& Ridha, B. H. Late-onset Tay-Sachs disease. Pract Neurol. 17(5), 396-9 (2017 Oct)

3. Myerowitz R., Piekarz R., Neufeld E. F., Shows, T. B. \& Suzuki, K. Human beta-hexosaminidase alpha chain: coding sequence and homology with the beta chain. Proc Natl Acad Sci USA, 82(23), 7830-4 (1985 Dec).

4. von Specht, B. U. et al. Enzyme replacement in Tay-Sachs disease. Neurology, 29(6), 848-54 (1979 Jun).

5. Hawkins-Salsbury, J. A., Cooper, J. D. \& Sands, M. S. Pathogenesis and therapies for infantile neuronal ceroid lipofuscinosis (infantile CLN1 disease). Biochim Biophys Acta, 1832(11), 1906-9 (2013 Nov).

6. Camp, L. A., Verkruyse, L. A., Afendis, S. J., Slaughter, C. A. \& Hofmann, S. L. Molecular cloning and expression of palmitoylprotein thioesterase. J Biol Chem, 269(37), 23212-9 (1994 Sep 16).

7. Lu, J. Y. et al. Intrathecal enzyme replacement therapy improves motor function and survival in a preclinical mouse model of infantile neuronal ceroid lipofuscinosis. Mol Genet Metab, 116(1-2), 98-105 (2015 Sep-Oct).

8. Schuchman, E. H., Desnick, R. J., Types, A. \& Niemann-Pick, B. Disease. Mol Genet Metab, 120(1-2), 27-33 (2017 Jan - Feb).

9. Quintern, L. E. et al. Isolation of cDNA clones encoding human acid sphingomyelinase: occurrence of alternatively processed transcripts. EMBO J, 8(9), 2469-73 (1989 Sep).

10. Dodge, J. C. et al. Intracerebroventricular infusion of acid sphingomyelinase corrects CNS manifestations in a mouse model of Niemann-Pick A disease. Exp Neurol, 215(2), 349-57 (2009 Feb).

11. Nestrasil, I. et al. Distinct progression patterns of brain disease in infantile and juvenile gangliosidoses: Volumetric quantitative MRI study. Mol Genet Metab, 123(2), 97-104 (2018 Feb).

12. Oshima, A., Tsuji, A., Nagao, Y., Sakuraba, H. \& Suzuki, Y. Cloning, sequencing, and expression of cDNA for human betagalactosidase. Biochem Biophys Res Commun, 157(1), 238-44 (1988 Nov 30).

13. Condori, J. et al. Enzyme replacement for GM1-gangliosidosis: Uptake, lysosomal activation, and cellular disease correction using a novel beta-galactosidase: RTB lectin fusion. Mol Genet Metab, 117(2), 199-209 (2016 Feb).

14. Pardridge, W. M. \& Boado, R. J. Reengineering biopharmaceuticals for targeted delivery across the blood-brain barrier. Methods Enzymol. 503, 269-92 (2012).

15. Boado, R. J. \& Pardridge, W. M. Genetic engineering of IgG-glucuronidase fusion proteins. J Drug Target, 18(3), 205-11 (2010 Apr).

16. Vidarsson, G., Dekkers, G. \& Rispens, T. IgG subclasses and allotypes: from structure to effector functions. Front Immunol. 5, 520 (2014).

17. Boado, R. J. et al. Genetic engineering of a lysosomal enzyme fusion protein for targeted delivery across the human blood-brain barrier. Biotechnol Bioeng, 99(2), 475-84 (2008 Feb 1).

18. Boado, R. J. \& Pardridge, W. M. Brain and Organ Uptake in the Rhesus Monkey in Vivo of Recombinant Iduronidase Compared to an Insulin Receptor Antibody-Iduronidase Fusion Protein. Mol Pharm, 14(4), 1271-7 (2017 Apr 3).

19. Boado, R. J., Hui, E. K., Lu, J. Z., Zhou, Q. H. \& Pardridge, W. M. Reversal of lysosomal storage in brain of adult MPS-I mice with intravenous Trojan horse-iduronidase fusion protein. Mol Pharm, 8(4), 1342-50 (2011 Aug 1).

20. Boado, R. J., Lu, J. Z., Hui, E. K. \& Pardridge, W. M. Reduction in Brain Heparan Sulfate with Systemic Administration of an IgG Trojan Horse-Sulfamidase Fusion Protein in the Mucopolysaccharidosis Type IIIA Mouse. Mol Pharm, 15(2), 602-8 (2018 Feb 5).

21. Sleat, D. E., Zheng, H., Qian, M. \& Lobel, P. Identification of sites of mannose 6-phosphorylation on lysosomal proteins. Mol Cell Proteomics, 5(4), 686-701 (2006 Apr).

22. Giugliani, R. et al. Neurocognitive and somatic stabilization in pediatric patients with severe Mucopolysaccharidosis Type I after 52 weeks of intravenous brain-penetrating insulin receptor antibody-iduronidase fusion protein (valanafusp alpha): an open label phase 1-2 trial. Orphanet J Rare Dis, 13(1), 110 (2018 Jul 5).

23. Lyly, A. et al. Glycosylation, transport, and complex formation of palmitoyl protein thioesterase 1 (PPT1)-distinct characteristics in neurons. BMC Cell Biol, 8, 22 (2007 Jun 12).

24. Ohto, U. et al. Crystal structure of human beta-galactosidase: structural basis of Gm1 gangliosidosis and morquio B diseases. J Biol Chem, 287(3), 1801-12 (2012 Jan 13).

25. Tropak, M. B. et al. Construction of a hybrid beta-hexosaminidase subunit capable of forming stable homodimers that hydrolyze GM2 ganglioside in vivo. Mol Ther Methods Clin Dev. 3, 15057 (2016).

26. Linke, T. et al. Stimulation of acid sphingomyelinase activity by lysosomal lipids and sphingolipid activator proteins. Biol Chem, 382(2), 283-90 (2001 Feb).

27. Bradbury, A. M. et al. Neurodegenerative lysosomal storage disease in European Burmese cats with hexosaminidase beta-subunit deficiency. Mol Genet Metab, 97(1), 53-9 (2009 May).

28. Dunlop, D. S., Yang, X. R. \& Lajtha, A. The effect of elevated plasma phenylalanine levels on protein synthesis rates in adult rat brain. Biochem J, 302 (Pt 2), 601-10 (1994 Sep 1).

29. Muenzer, J. \& Fisher, A. Advances in the treatment of mucopolysaccharidosis type I. N Engl J Med, 350(19), 1932-4 (2004 May 6).

30. Jeyakumar, M. et al. Neural stem cell transplantation benefits a monogenic neurometabolic disorder during the symptomatic phase of disease. Stem Cells, 27(9), 2362-70 (2009 Sep).

31. Lu, J. Y., Hu, J. \& Hofmann, S. L. Human recombinant palmitoyl-protein thioesterase-1 (PPT1) for preclinical evaluation of enzyme replacement therapy for infantile neuronal ceroid lipofuscinosis. Mol Genet Metab, 99(4), 374-8 (2010 Apr).

32. Hu, J. et al. Intravenous high-dose enzyme replacement therapy with recombinant palmitoyl-protein thioesterase reduces visceral lysosomal storage and modestly prolongs survival in a preclinical mouse model of infantile neuronal ceroid lipofuscinosis. Mol Genet Metab, 107(1-2), 213-21 (2012 Sep).

33. Ziegler, R. J. et al. Distribution of acid sphingomyelinase in rodent and non-human primate brain after intracerebroventricular infusion. Exp Neurol, 231(2), 261-71 (2011 Oct).

34. Dearborn, J. T. et al. Histochemical localization of palmitoyl protein thioesterase-1 activity. Mol Genet Metab, 117(2), 210-6 (2016 Feb).

35. Hobert, J. A. \& Dawson, G. Neuronal ceroid lipofuscinoses therapeutic strategies: past, present and future. Biochim Biophys Acta, 1762(10), 945-53 (2006 Oct). 
36. He, X. et al. Characterization of human acid sphingomyelinase purified from the media of overexpressing Chinese hamster ovary cells. Biochim Biophys Acta, 1432(2), 251-64 (1999 Jul 13).

37. $\mathrm{Bu}$, J. et al. Merits of combination cortical, subcortical, and cerebellar injections for the treatment of Niemann-Pick disease type A. Mol Ther, 20(10), 1893-901 (2012 Oct).

38. Samoylova, T. I. et al. Generation and characterization of recombinant feline beta-galactosidase for preclinical enzyme replacement therapy studies in GM1 gangliosidosis. Metab Brain Dis, 23(2), 161-73 (2008 Jun).

39. Zhang, S. et al. Kinetic mechanism and characterization of human beta-galactosidase precursor secreted by permanently transfected Chinese hamster ovary cells. Biochem J, 304 (Pt 1), 281-8 (1994 Nov 15).

40. Hahn, C. N. et al. Generalized CNS disease and massive GM1-ganglioside accumulation in mice defective in lysosomal acid betagalactosidase. Hum Mol Genet, 6(2), 205-11 (1997 Feb).

41. Weismann, C. M. et al. Systemic AAV9 gene transfer in adult GM1 gangliosidosis mice reduces lysosomal storage in CNS and extends lifespan. Hum Mol Genet, 24(15), 4353-64 (2015 Aug 1).

42. Tan. L. K., Shopes, R. J., Oi, V. T. \& Morrison, S. L. Influence of the hinge region on complement activation, C1q binding, and segmental flexibility in chimeric human immunoglobulins. Proc Natl Acad Sci USA, 87(1), 162-6 (1990 Jan).

43. Boado, R. J., Lu, J. Z., Hui, E. K., Lin, H. \& Pardridge, W. M. Insulin Receptor Antibody-alpha-N-Acetylglucosaminidase Fusion Protein Penetrates the Primate Blood-Brain Barrier and Reduces Glycosoaminoglycans in Sanfilippo Type B Fibroblasts. Mol Pharm, 13(4), 1385-92 (2016 Apr 4).

44. Tropak, M. B., Reid, S. P., Guiral, M., Withers, S. G. \& Mahuran, D. Pharmacological enhancement of beta-hexosaminidase activity in fibroblasts from adult Tay-Sachs and Sandhoff Patients. J Biol Chem, 279(14), 13478-87 (2004 Apr 2).

45. van Diggelen, O. P. et al. A rapid fluorogenic palmitoyl-protein thioesterase assay: pre- and postnatal diagnosis of INCL. Mol Genet Metab, 66(4), 240-4 (1999 Apr)

46. van Diggelen, O. P. et al. A new fluorimetric enzyme assay for the diagnosis of Niemann-Pick A/B, with specificity of natural sphingomyelinase substrate. J Inherit Metab Dis. 28(5), 733-41 (2005).

\section{Acknowledgements}

The authors are indebted to Winnie Tai, Phuong Tran, and Stephanie Lee for valuable technical assistance, and to Dr. Mathias Schmidt for valuable discussions.

\section{Author contributions}

R.J.B. and W.M.P. designed the fusion genes, and R.J.B. supervised the experiments; J.Z.L., E.K.-W.H. and H.L. executed the experiments; W.M.P. wrote the manuscript, and all authors edited the manuscript.

\section{Competing Interests}

R.J.B., J.Z.L., E.K.-W.H. and H.L. are employees of ArmaGen, and W.M.P. is consultant to ArmaGen.

\section{Additional information}

Correspondence and requests for materials should be addressed to W.M.P.

Reprints and permissions information is available at www.nature.com/reprints.

Publisher's note Springer Nature remains neutral with regard to jurisdictional claims in published maps and institutional affiliations.

Open Access This article is licensed under a Creative Commons Attribution 4.0 International License, which permits use, sharing, adaptation, distribution and reproduction in any medium or format, as long as you give appropriate credit to the original author(s) and the source, provide a link to the Creative Commons license, and indicate if changes were made. The images or other third party material in this article are included in the article's Creative Commons license, unless indicated otherwise in a credit line to the material. If material is not included in the article's Creative Commons license and your intended use is not permitted by statutory regulation or exceeds the permitted use, you will need to obtain permission directly from the copyright holder. To view a copy of this license, visit http://creativecommons.org/licenses/by/4.0/.

(C) The Author(s) 2019 